\title{
Food Restriction Programs and Their Applications in
}

\section{Fish Aquaculture}

Daniel Pereira da Costa ${ }^{1,2}$, Giovanni Resende de Oliveira ${ }^{3}$, Tainára Cunha Gemaque ${ }^{2}$, Daniele Salgueiro de Melo ${ }^{2}$ and Leonardo Vaz Pereira ${ }^{4}$

1. University of Amapa State (UEAP), Campus Lakes Territory, Amapá, AP 68950-000, Brazil

2. Aquaculture Laboratory (LAQUA/UFMG), Pós Graduate Program in Zootecnia, Federal University of Minas Gerais, Campus Pampulha, Belo Horizonte, MG 31270-010, Brazil

3. Agricultural Research Company of Minas Gerais (EPAMIG), Experimental Field of Leopoldina, Leopoldina, MG 36700-000, Brazil

4. Federal Rural University of Amazon (UFRA), Campus Parauapebas, Parauapebas, PA 68515-000, Brazil

\begin{abstract}
Food restriction is a strategy to improve the productive efficiency of some aquatic organisms. It is expected with the implementation of food restriction programs to first reduce the feed consumption by the cultivated species and consequently reduce the waste load in the water. In addition, there is a lower employment of labor during periods of food restriction. However, the efficiency of the feed restriction and the compensatory gain of weight by the organisms cultivated will depend on the adaptation and the characteristics of the species in question. Several methodologies have tested forms of food restriction applied to fish farming. Some of them are addressed in this review, as well as results and comparisons made with several authors on the subject in question. The purpose of this paper was to describe the main reasons for using food restriction, its implications on fish organism and to compare results from previous studies
\end{abstract}

Key words: Fasting, fish farming, cost reduction, digestive physiology, compensatory gain.

\section{Introduction}

Food restriction is a natural phenomenon, which is present in part of fish life in nature [1, 2] and can be used as a management strategy in the production of aquatic organisms. In order to improve the sustainability of the business with the economy of ration, labor, environmental resources and to meet the characteristics of the behavior and metabolism of the animal involved, this topic has been much discussed today and aims to be an innovation in food programs with criteria defined by species-specific characteristics, age and reproductive phase, production systems and food composition offered.

Efficient food programs and maximum utilization

Corresponding author: Daniel Pereira da Costa, Ph.D., research fields: aquaculture, production systems, nutrition and sustainability. of food nutrients are the main concern of the aquaculture sector, given the prediction of a high world demand for fish in the short and medium term. It is expected that food restriction programs will be implemented primarily to reduce feed consumption by aquatic organisms, avoiding excessive feed costs which represent $60 \%$ to $70 \%$ of the production cost in this segment. This can also prevent overfeeding, a process in which animals ingest a larger amount of food than their digestion and absorption capacity, which leads to a higher metabolic expenditure and part of the food is eliminated in the faeces without having been used [3].

With the optimization of feed consumption and consequently the lower use of this input, the waste load will be reduced in the productive systems and as a consequence, the contribution of pollutants in the water will be reduced, minimizing the environmental 
impact of the productive activity in the place and even the increase of the density of animals stored in the production units [4].

Depending on the type of restriction adopted, it is possible to dispense some of the workforce for some time (weekly- $1 \mathrm{~d}$ or $2 \mathrm{~d}$ ) or decrease the daily feed frequency. Another important point is the verification of the quality of the carcass of the animals when they undergo the food restriction in order to avoid losses in the proportion of fillet that is the part used in the food industry [5].

A restriction program in commercial fish breeding should avoid some problems that may occur due to incompatibility of food management and metabolism of aquatic organisms, such as feedback hyperphagia, which may impair the normal digestive process. In cases of severe restrictions that cause physical damage resulting in poor feed efficiency, when food can no longer meet the animal's needs, catabolism can impair carcass weight and cuts and cause damage to the gastrointestinal tract due to lack of food [6, 7]. This process may also cause damage to the expression pattern of genes linked to the production of hormones and intracellular transporters, leading to decreased immunity and increased mortality [8].

It is recommended that for a food restriction programs aquatic organisms undergo periods of initial fasting, mobilizing their glycogen stores and avoiding chronic fasting, where the lipid reserves and the skeletal muscle protein are consumed. In this way, the post-fasting compensatory gain will be efficient by providing a value equal to or very close to that obtained with the feed supplied in the conventional manner without restrictions [6].

The purpose of this paper was to describe the main reasons for using food restriction, its implications on fish organism and to compare results from previous studies.

\section{Strategy Overview}

Compensatory growth is accelerated anabolic physiological behavior over a period of time when animals recover development after a period of deprivation leading them to limit normal metabolism. Fish exhibit this ability in an exacerbated manner [9]. This characteristic makes the food restriction techniques successfully employed in different species of commercial interest $[10,11]$. Compensatory growth is the precondition for success in food restriction programs which, together with the anatomical-physiological and bromatological responses, will corroborate the ability of the species to adapt to the proposed management condition [12].

Metabolic responses to fluctuations in food availability vary depending on several factors, such as species, age and fish size [13-15]. Different fish species exhibit distinct strategies for dealing with periods of food deprivation and fasting, including varying the use of carbohydrates, lipids and proteins from different body compartments [16].

The consequences of fasting on metabolism are more pronounced in larvae and juvenile stages than in adult fish, probably due to a lower amount of energy reserves [6, 17]. Concomitantly, external conditions such as temperature may also influence the metabolic response in food deprivation situations [15, 16, 18].

According to the duration of the fasting period there are two physiologically different states. The first is related to the initial stages of fasting (periods shorter than 7-10 d) and is characterized by the rapid mobilization of available reserves. The second is linked to chronic periods of fasting, associating with pronounced lipid and protein catabolism, as well as weight loss [19].

There seems to be no more accurate characterization of the types of fasting in fish as to their duration and intensity. The classification of the fasting type as to its short, medium and long duration, as well as a practical distinction between moderate and severe fasting, would facilitate the provision of information about the subject, as well as a more appropriate comparison of the research data. 
During metabolic adaptation to fasting and feedback situations there are a number of modifications in the intermediate metabolism of carbohydrates, lipids and proteins in order to maintain homeostasis [20, 21]. The major modifications occur in the more active organs of the intermediate metabolism, such as the liver, brain and skeletal muscle, and are regulated by the nervous and endocrine system [22-24].

Some studies have shown that variable food intake and feedback lead to increased tissue mass, protein content and enzymatic activities in a synchronized manner with response to fasting, possibly due to the combination of increased cell proliferation [25], high rates of protein synthesis, and low levels of protein degradation [23, 24].

Thus, from the point of view of commercial fish farms, if there are strategies of food restriction that do not imply a significant reduction of growth rates, it is preferable for economic and environmental reasons, as well as for the better quality of the final product [25]. During the first days of fasting there is a mobilization of glycogen in all organs, whereas as the fasting period increases, both lipids and proteins are used as energetic substrates by intermediary metabolic routes such as ketogenesis and gluconeogenesis [26].

Bosworth and Wolters [27] studied the effect of food restriction on catfish Ictalurus punctatus (weight $=0.77 \mathrm{~kg}$ ) grown in $400 \mathrm{~m}^{2}$ nurseries during four weeks, with one group being fed once a week to satiety and the other group totally private. Analysis of visceral components and carcass yield and fillets was performed in the second and fourth weeks of the test. Interestingly, it was found that although the fillet yield was significantly reduced, the carcass yield did not show significant changes in fish under feed restriction. In this sense, the compensatory growth phenomenon should not be analyzed in isolation, as this may lead to hasty and/or mistaken conclusions in terms of economic viability, when food restriction plans are to be applied in commercial fish farms.
While Tian and Qin [28] observed increase in ash content of barramundi juveniles (Lates calcarifer) under total food deprivation for two weeks, compared to the control group, Abdel-Hakim et al. [5] detected increased moisture content, ashes and protein in the carcass of hybrid juveniles of tilapia (Oreochromis niloticus $\times O$. aureus) with food deprivation of $3 \mathrm{~d}$ per week, compared to the control group, while the values of ethereal extract and energy were reduced.

Food strategies should focus on the increase of skeletal fish musculature, which is one of the main zootechnical objectives of fish farming, since the muscle comprises the edible fraction of these animals [29]. However, the compensatory gain should be accompanied by improvement in fish feed efficiency and maintenance of the fish's nutritional quality and normal industrial yields and their respective cuts. Otherwise, the adoption of plans with severe food restriction could lead to economic loss due to the increase in food consumption and/or a decrease in industrial incomes.

\section{Practical Observations and Their Implications}

When evaluating the effect of restriction cycles on proteolytic activity in tilapia (O. mossambicus), Chan et al. [30] concluded that $1 \mathrm{~d}$ of fasting after fasting (3, 5 and 7 d) is insufficient to lead to recovery and activation of growth in fish. In addition, it is imperative that the food and economic efficiency indices be carefully evaluated in quantitative food restriction assays, since most of the assays have adopted feedback to satiety, where the presence of hyperphagia (increased food consumption) is evidenced.

In the more advanced stages of fish fattening, the producer must aim at efficient feed conversion, even if this penalizes the growth rate somewhat. Some studies have shown that short periods of food deprivation [28, 31] or multiple periods of food deprivation and feedback increase feed efficiency and growth in 
several fish species [30]. The increase in dietary intake and rapid weight gain in fish during the recovery period has been accompanied by improved feed conversion [32, 33]. In some cases, fish under feed restriction showed better feed efficiency without increased intake of food [32, 34, 35].

In the cost-benefit analyses of tilapia diets, the results suggest a reduction in food costs through moderate food deprivation at $1 \mathrm{~d}$ or $2 \mathrm{~d}$ per week, with the same growth and good performance with cost reduction. However, harsher deprivations generated bad results [8].

The partial reduction of food aiming not at time, but the amount of food supplied is another strategy used in food restriction programs. Silva et al. [36] studied the effect of feed restriction on zootechnical performance and feed cost in mullet juveniles (Mugil liza). Five feeding rates were tested with $100 \%, 80 \%$, $60 \%, 40 \%$ and $20 \%$ satiety, with three replicates each. Juveniles with $0.21 \pm 0.03 \mathrm{~g}(n=30)$ were distributed in 15 200-L tanks. Survival was greater than $93 \%$ and there was no influence of treatments on this variable. The specific growth rate in $100 \%$ satiety treatment was $5.96 \% \pm 0.18 \%$ per day and the final weight was nearly six times greater than the initial one. Treatment hems with $20 \%$ of satiety had a lower hepatosomatic rate, hepatocytes and smaller nuclei, and a lower reserve of glycogen in the liver than the other treatments. Reducing the feed rate impaired the growth of mullet juveniles. However, a feeding rate around $72 \%$ of the satiety was able to promote the best use of the food consumed, with a $28 \%$ reduction in the cost of the ration. In this work, a positive response was presented from the financial point of view in the quantitative restriction of food, even if no test was done to evaluate the quality of the fish carcass.

While Gonçalves et al. [37] verified the effects of feed restriction on piapara juveniles (Leporinus elongatus). Eighty-four (84) fish were divided in three treatments, one control group with daily feeding; a group of animals that did not receive food on weekends and a group of animals submitted to food restriction on 21 consecutive days. The study was conducted for $78 \mathrm{~d}$ when the fish passed the final evaluation before evaluations were done at $21 \mathrm{~d}$ and 42 d. Fish submitted to food restriction for 21 consecutive days and animals that did not receive food on weekends, presented total compensatory growth after feedback. In this study, it can be observed that this species has great capacity to face long periods of fasting without productive loss, perhaps due to the wild characteristic of this fish that can go through extensive periods without food in nature.

In one study, Kojima et al. [38] evaluated the effects of different fasting periods on survival rate, growth, muscle development and compensatory growth in pacu (Piaractus mesopotamicus) for $5 \mathrm{~d}$ larvae. The larvae were submitted to $0,2,4,6$ or 8 consecutive days of fasting and then fed for another $10 \mathrm{~d}$ with nauplii of artemia in the laboratory. Subsequently, these fish were transferred to a tank excavated in semi-intensive system for another $30 \mathrm{~d}$. After the fasting period, the larvae presented weight reduction, loss of muscle mass and decrease of the diameter of the muscle fibers, after the feedback during 10 regular days. Pacu larvae are capable of compensatory growth, provided that fasting does not exceed 2 d, so subsequent growth and muscle development performance will not be affected. This short period of fasting can serve as an emergency strategy in the management of this species in commercial crops. In this work it is observed that there was a more careful evaluation not only of the weight gain but also of the fish musculature to be able to recommend a more adequate food restriction program.

In another study Urbinati et al. [7] alleviated the compensatory growth capacity in matrinxã (Brycon amazonicus) juveniles using three feeding protocols for $60 \mathrm{~d}$ : daily feeding; feeding deprivation for $2 \mathrm{~d}$ and feedback in $3 \mathrm{~d}$; feeding deprivation for $2 \mathrm{~d}$ and 
feedback in $4 \mathrm{~d}$. Then all fish groups were fed ad libitum daily for $15 \mathrm{~d}$. In the first phase, fish achieved a full compensatory growth at two deprivation levels, increasing feed intake and improving feed conversion. In fasting treatments there was a feed saving of $36 \%$ (in the first) and $40 \%$ (in the second). In the second stage, growth was similar for all fish. Feed consumption increased in both food deprivate levels, but food efficiency did not differ between treatments, demonstrating that when food is consumed at will there is a low efficiency of feed utilization. The authors state that restriction programs are a way of saving food and making the activity economically viable. However, in this work there was no qualitative evaluation of the carcass of the animals.

\section{Conclusions}

The use of compensatory growth in fish farming should not necessarily focus only on the achievement of some isolated effects. This occurs, for example, when reference is made to the ability of some fish to undergo dietary restriction to demonstrate the ability to reach final weights similar to that of continuously fed fish. The reactions of the animal organism are much more complex involving physiological and behavioral factors, as well as other adaptive mechanisms yet unknown that aim at the homeostasis of the organism and the survival of the animal itself.

Thus, the compensatory gain or growth phenomenon should not be understood as an essential implication for the food restriction assays to obtain satisfactory results but rather as one of the means for such. Even if there are no direct effects from the compensatory gain in a given batch of farmed fish, it is possible that they achieve better food efficiency through the adoption of food management capable of meeting, with precision and convenience, their food quality/quantity requirements and their physiological and behavioral characteristics, respectively. Additionally, this food management should prevent the occurrence of feed waste, generated both by non-consumption and losses to the aquatic environment as well as by occurrence of overfeeding.

However, it is verified that food strategies more in keeping with the dynamics of metabolic self-regulation of each species, and in line with other technological inputs such as precision genetics and nutrition, also present great potential for the improvement of economic results in the aquaculture segment.

\section{References}

[1] Rios, F. S., Kaiinin, A. L., and Rantin, F. T. 2002. “The Effects of Long-Term Food Deprivation on Respiratory and Hematology of the Neotropical Fish Hoplias malabaricus.” J. Fish. Biol. 1 (1): 85-95.

[2] Midwood, J. D., Larsen, M. H., Aarestrud, K., and Cooke, S. J. 2016. "Stress and Food Deprivation: Linking Physiological State to Migration Success in a Teleostei Fish.” J. Experimen Biol. 219 (23): 3712-8.

[3] Lee, S., Lee, M., Kim, K.-H., Kim, H. G., Park, C.-J., Park, J.-W., Noh, G. E., and Kim, W. 2018. “Availability on Growth Performance and Immune-Related Gene Expression of Juvenile Olive Flowder (Paralichthys olivaceus).” Fish Shellfish Immunol. 80: 348-56.

[4] Einen, O., Mørkøre, T., Rørå, A. M. B., and Thomassen, M. S. 1999. "Feed Ration Prior to Slaughter-A Potential Tool for Managing Product Quality of Atlantic Salmon (Salmo salar).” Aquaculture 178: 149-69.

[5] Abdel-Hakim, N. F., State, A. A. H., Al-Azab, A. A., and El-Khely, K. F. 2009. "Effect of Feeding Regimes on Growth Performance of Juvenile Hybrid Tilapia (Oreochromis niloticus $\times$ Oreochromis aureus)." World J. Agric. Sci. 5 (1): 49-54.

[6] Richard, P., Bergeron, J., Boulhic, M., Galios, R., and Person-Le Ruyet, J. 1991. "Effect of Starvation on RNA, DNA and Protein Content of Laboratory-Reared Larvae and Juveniles of Solea solea.” Mar. Ecol. Prog. Ser. 72: 69-77.

[7] Urbinati, E. C., Jiménez-Sarmiento, S., and Takahashi, L. S. 2014. "Short-Term Cycles of Feed Deprivation and Refeeding Promote Full Compensatory Growth in the Amazon Fish Matrinxã (Brycon amazonicus)." Aquaculture 433: 430-3.

[8] Delgadim, T., Perez-Sirkin, D., Di Yorio, M., Arranz, S., and Vissio, P. 2015. "GH, IGF-I and GH Receptors mRNA Expression in Response to Growth Impairment Following a Food Deprivation Period in Individually Housed Cichlid Fish Cichlasoma dimerus.” Fish Physiol. Biochem. 4 (1): 51-60. 
[9] Won, E. T., and Borski, R. J. 2013. "Endocrine Regulation of Compensatory Growth in Fish.” Front. Endocrinol. 4: 1-13.

[10] Ribeiro, F. F., and Tsuzuki, M. Y. 2010. “Compensatory Growth Responses in Juvenile Fat Snook Centropomus paralelus Poey, Following Food Deprivation.” Aquac. Res. 4: 226-33.

[11] Mohanty, R. K. 2015. "Effects of Feed Restriction on Compensatory Growth Performance of Indian Major Carps in a Carp-Prawn Polyculture System: A Response to Growth Depression.” Aquac. Nut. 21: 464-73.

[12] Landeira-Dabarca, A., Álvarez, M., and Molist, P. 2014. "Food Deprivation Causes Rapid Changes in the Abundance and Glucidic Composition of the Cutaneous Mucous Cells of Atlantic Salmon Salmo salar L.” J. Fish Dis. 37: 899-909.

[13] Stimpson, J. H. 1965. "Comparative Aspects of the Control of Glycogen Utilization in Vertebrate Liver." Comp. Biochem. Physiol. 15 (2): 187-97.

[14] Méndez, G., and Wieser, W. 1993. "Metabolic Responses to Food Deprivation and Refeeding in Juveniles of Rutilus rutilus (Teleosteei: Cyprinidae).” Envir. Biol. Fish 36: 73-81.

[15] Shimeno, S., Kheyyali, D., and Takeda, M. 1990. "Metabolic Adaptation to Prolonged Starvation in Carp." Nippon Suisan Gakk. 56 (1): 35-41.

[16] Bandeen, A., and Leatherland, J. F. 1997. "Transportation and Handling Stress of White Suckers Raised in Cages.” Aquac. Int. 5: 385-96.

[17] Gadomski, D. M., and Petersen, J. H. 1998. "Effects of Food Deprivation on the Larvae of Two Flatfishes." Mar. Ecol. Prog. Ser. 44: 103-11.

[18] Brett, J. R. 1979. "Fish Physiology.” In Environmental Factors and Growth, edited by Hoar, W. S., Randall, D. J., and Brett, J. R., Vol. 8. London: Academic Press, 599-675.

[19] Farbridge, K. J., and Leatherland, J. K. 1992. “Temporal Changes in Plasma Thyroid Hormone, Growth Hormone and Free Fatty Acid Concentrations, and Hepatic 5'-Monodeiodinase Activity, Lipid and Protein Content during Chronic Fasting and Re-feeding in Rainbow Trout (Oncorhynchus mykiss)." Fish Physiol. Biochem. 10: 245-57.

[20] Bastrop, R., Spangenberg, R., and Jürss, K. 1991. "Biochemical Adaptation of Juvenile Carp (Cyprinus carpio L.) to Food Deprivation.” Comp. Biochem. Physiol. 98A (1): 143-9.

[21] Walton, M. J., and Cowey, C. B. 1982. "Aspects of Intermediary Metabolism in Salmonid Fish.” Comp. Biochem. Physiol. 73B: 59-79.

[22] Murat, J. C., Plisetskaya, E. M., and Woo, N. Y. S. 1981. "Endocrine Control of Nutrition in Cyclostome and Fish."
Comp. Biochem. Physiol. 68A: 149-58.

[23] Krogdahl, A., and Bakke-Mckellep, A. M. 2005. "Fasting and Refeeding Cause Rapid Changes in Intestinal Tissue Mass and Digestive Enzyme Capacities of Atlantic Salmon (Salmo salar L.)." Comp. Biochem. Physiol. 141A: 450-60.

[24] Houlihan, D. F., Hall, S. J., Gray, C., and Noble, B. S. 1988. "Growth Rates and Protein Turnover in Atlantic Cod, Gadus morhua.” Canadian. J. Fish. Aquat. Sci. 45: 961-4.

[25] Eroldogan, O. T., Kumla, M., Kiris, G. A., and Sezer, B. 2006. "Compensatory Growth Response of Sparus aurata Following Different Starvation and Refeeding Protocols." Aquac. Nutr. 12: 203-10.

[26] Vigliano, F. A., Quiroga, M. I., and Nieto, J. M. 2014. "Metabolic Adaptation to Food Deprivation and Refeeding in Fish.” Rev. Ictiol. 10: 79-108.

[27] Bosworth, B. G., and Wolters, W. 2005. "Effects of Short-Term Feed Restriction on Production, Processing and Body Shape Traits in Market - Weight Channel Catfish, Ictalurus punctatus (Rafinesque).” Aquac. Res. 369 (4): 344-51.

[28] Tian, X., and Qin, J. G. 2004. "Effects of Previous Ration Restriction on Compensatory Growth in Barramundi Lates calcarifer.” Aquaculture 235 (1-4): 273-83.

[29] Leitão, N. J., Dal-Pai-Silva, M., Almeida, F. L. A., and Portrella, M. C. 2011. "The Influence of Initial Feeding on Muscle Development and Growth in Pacu Piaractus mesopotamicus Larvae.” Aquaculture 315: 78-85.

[30] Chan, C., Lee, D., Cheng, Y., Hsieh, D. J., and Weng, C. 2008. "Feed Deprivation and Refeeding on Alterations of Proteases in Tilapia Oreochromis mossambicus.” Zool. Stud. 47 (2): 207-14.

[31] Rueda, F. M., Martinez, F. J., Zamora, S., Kentouri, M., and Divanach, P. 1998. "Effect of Fasting and Refeeding on Growth and Body Composition of Red Porgy, Pagrus pagrus L.” Aquac. Res. 29: 447-52.

[32] Russell, N. R., and Wootton, R. J. 1992. “Appetite and Growth Compensation in the European Minnow, Phoxinus phoxinus (Cyprinidae) Following Short Term of Food Restriction.” Environm. Biol. Fishes 34: 277-85.

[33] Jobling, M., and Johansen, S. J. S. 1999. "The Lipostat, Hyperphagia and Catch-Up Growth.” Aquac. Res. 30: 473-8.

[34] Eroldogan, O. T., Kumlu, M., and Aktas, M. 2004. “Optimum Feeding Rates for European Sea Bass Dicentrachus labrax L. Reared in Seawater and Freshwater.” Aquaculture 231: 501-15.

[35] Stefánsson, M. Ö., Reinert, J., Sigurðsson, K. K., Nedreaas, K., and Pa Mpoulie, C. 2009. "Depth as a Potential Driver of Genetic Structure of Sebastes mentella across the North Atlantic Ocean.” ICES J. Mar. Sci. 66: 
680-90.

[36] Silva, E. M., Sampaio, L. A. S., Martins, G. B., Romano, L. A., and Tesser, M. B. 2013. "Zootechnical Performance and Feeding Costs of Mullet Juveniles Subjected to Feed Restriction.” Pesq. Agrop. Bras. 48 (8): 906-12. (in Portuguese)

[37] Gonçalves, A. F. N., Ha, N., Biller-Takahashi, J. D., Sato, L. S., Kishimoto, M. K., and Takahashi, L. S. 2014.
"Stocking Density and Food Restriction in Piapara Juveniles.” Bol. Inst. Pesca 40: 431-9. (in Portuguese)

[38] Kojima, J. T., Leitão, N. J., Menossi, O. C. C., Freitas, T. M., Dal-Pai Silva, M., and Portella, M. C. 2015. "Short Periods of Food Restriction Do Not Affect Growth, Survival or Muscle Development on Pacu Larvae.” Aquaculture 436: 137-42. 